\title{
Dynamic evaluation of the contractile function of lumbodorsal muscles during locust pose in yoga by real-time ultrasound
}

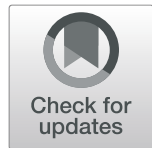

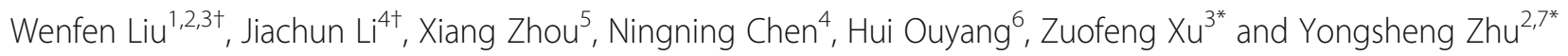

\begin{abstract}
Background and Purpose: Chronic low back pain (CLBP), which has a close relationship with lumbar muscle degeneration, can be effectively treated by exercise therapy, and yoga has been widely accepted by clinicians and patients with CLBP. The purpose of this study was to observe the changes in the thickness of lumbodorsal muscles that occur during locust pose in yoga and how these changes occur. From the changes in muscle thickness that occur in the locust pose, the contractile function of lumbodorsal muscles can be evaluated.

Methods: Fifty-two healthy volunteers (from May 2019 to August 2019, age from 28 to 68 years, 23 males and 29 females (age: $40 \pm 8$ years; weight: $68.3 \pm 5.2 \mathrm{~kg}$; height: $170.2 \pm 13.1 \mathrm{~cm}$ ) were recruited, and lumbodorsal muscle, including the multifidus, longissimus, iliocostalis, and quadratus lumborum, ultrasonic examinations were carried out in the relaxed and contracted states. The changes in the thickness of the lumbodorsal muscles in the relaxed and contracted states were dynamically observed by real-time ultrasound when subjects were performing the locust yoga pose. Then, the thicknesses of the muscles during the two states were measured to calculate the ratio of contraction of each muscle and determine the statistical significance of the change in thickness of each muscle.
\end{abstract}

\footnotetext{
*Correspondence: xuzuofeng77@aliyun.com; 1946295663@qq.com

${ }^{3}$ Department of Ultrasound, The Seventh Affiliated Hospital of Sun Yat-Sen

University, 628\# Zhenyuan Road, 518100 Shenzhen, Guangdong, China

${ }^{2}$ The Third School of Clinical Medicine, Southern Medical University,

Guangzhou, China

Full list of author information is available at the end of the article
}

(c) The Author(s). 2021 Open Access This article is licensed under a Creative Commons Attribution 4.0 International License, which permits use, sharing, adaptation, distribution and reproduction in any medium or format, as long as you give appropriate credit to the original author(s) and the source, provide a link to the Creative Commons licence, and indicate if changes were made. The images or other third party material in this article are included in the article's Creative Commons licence, unless indicated otherwise in a credit line to the material. If material is not included in the article's Creative Commons licence and your intended use is not permitted by statutory regulation or exceeds the permitted use, you will need to obtain permission directly from the copyright holder. To view a copy of this licence, visit http://creativecommons.org/licenses/by/4.0/ The Creative Commons Public Domain Dedication waiver (http://creativecommons.org/publicdomain/zero/1.0/) applies to the data made available in this article, unless otherwise stated in a credit line to the data. 
Results: The mean thickness of the left multifidus in the relaxed state was $1.32 \pm 0.27 \mathrm{~cm}(95 \% \mathrm{Cl}: 1.24 \sim 1.39)$, that in the contracted state was $1.60 \pm 0.30 \mathrm{~cm}(95 \% \mathrm{Cl}: 1.52 \sim 1.69)$ (obviously different between the relaxed and contracted states, $P<0.001)$, and those in the corresponding right side were $1.37 \pm 0.31 \mathrm{~cm}(95 \% \mathrm{Cl}: 1.29 \sim 2.46)$ and $1.68 \pm 0.38 \mathrm{~cm}(95 \% \mathrm{Cl}: 1.58 \sim 1.79)(P<0.001)$, respectively. The mean thickness of the left quadratus lumborum in the relaxed state was $1.38 \pm 0.32 \mathrm{~cm}(95 \% \mathrm{Cl}: 1.29 \sim 1.47)$, that in the contracted state was $1.62 \pm$ $0.40 \mathrm{~cm}(95 \% \mathrm{Cl}: 1.50 \sim 1.73)(P=0.001)$, and those in the corresponding right side were $1.30 \pm 0.32 \mathrm{~cm}(95 \% \mathrm{Cl}$ : $1.21 \sim 1.39)$ and $1.55 \pm 0.41 \mathrm{~cm}(95 \% \mathrm{Cl}: 1.44 \sim 1.67)(P=0.001)$, respectively. The mean thickness of the left longissimus in the relaxed was $2.33 \pm 0.51 \mathrm{~cm}(95 \% \mathrm{Cl}: 2.19 \sim 2.47)$, that in the contracted state was $3.20 \pm 0.61 \mathrm{~cm}$ (95\% Cl: $3.03 \sim 3.37)(P<0.001)$, and those in the corresponding right side were $2.34 \pm 0.49 \mathrm{~cm}(95 \% \mathrm{Cl} 2.20 \sim 2.48)$ and $3.26 \pm 0.68 \mathrm{~cm}(95 \% \mathrm{Cl} 3.07 \sim 3.45)(P<0.001)$, respectively. The mean thickness of the left iliocostalis in the relaxed state was $1.88 \pm 0.41 \mathrm{~cm}(95 \% \mathrm{Cl}: 1.76 \sim 1.99)$, that in the contracted state was $2.34 \pm 0.49 \mathrm{~cm}$ (95\% Cl: 2.00 $\sim 2.47)(P<0.001)$, and those in the corresponding right side were $1.98 \pm 0.40 \mathrm{~cm}(95 \% \mathrm{Cl}: 1.87 \sim 2.09)$ and $2.44 \pm$ $0.56 \mathrm{~cm}(95 \% \mathrm{Cl}: 2.29 \sim 2.60)(P<0.001)$, respectively. The mean contracted state/resting state (C/R) of the longissimus was $1.39 \pm 0.14$ on the left and $1.40 \pm 0.16$ on the right. The multifidus and iliocostalis had the second highest $C / R$. The mean $C / R$ of the multifidus was $1.23 \pm 0.12$ on the left and $1.24 \pm 0.15$ on the right, and the mean $\mathrm{C} / \mathrm{R}$ of the iliocostalis was $1.25 \pm 0.12$ on the left and $1.24 \pm 0.14$ on the right. The quadratus lumborum had the lowest $C / R$, and the mean $C / R$ of the quadratus lumborum was $1.17 \pm 0.10$ on the left and $1.19 \pm 0.11$ on the right.

Conclusions: Ultrasound can be used to dynamically assess the contractile function of the lumbar muscle in the locust pose of yoga, the $\mathrm{C} / \mathrm{R}$ ratio can be used to indicate the ability of a muscle to contract, and dynamic ultrasound can guide lumbar exercise and feedback the exercise results. The establishment of this model allowed data regarding the contraction state of the lumbar muscle to be obtained in a normal population, and based on this, future studies can further explore and evaluate the contraction state of the lumbar muscle after yoga exercise in CLBP patients, the effect exercise on lumbar instability and on a patient population after lumbar operation.

Keywords: Lumbodorsal muscles, muscle thickness, locust yoga pose, ultrasonography, low back pain

\section{Introduction}

Low back pain (LBP) is defined as pain and discomfort localized above the inferior gluteal folds and below the costal margin, regardless of whether leg pain is involved $[1,2]$. Chronic LBP (CLBP) is defined as a minimum of 12 weeks of LBP [2], and it is the leading cause of years lived with disability in both developed and developing countries and sixth in terms of overall disease burden[3-5]. Despite the very high prevalence and severe consequences of this disease, its pathophysiology is poorly understood[6], systematic literature reviews have indicated that physical exercises are effective in reducing pain and disability in patients [7-9].

Exercise training is an effective treatment for nonspecific CLBP, the European guidelines released in 2006 recommend supervised exercise therapy as a first-line treatment in the management of this pain[10], however, the best mode of exercise training is unknown[2]. Yoga, which originated in ancient India and has been widely accepted by those clinicians and patients[11-18], could reduce pain better than nonexercise training comparators[19]. A practice guideline from the American College of Physicians and American Pain Society lists a specific style of yoga as having fair evidence of a moderate benefit $[9,11]$. This is particularly useful when the new therapy may have other potential benefits, such as a lower cost[16]. However, the mechanism by which yoga relieves pain and dysfunction cannot be explained by the existing research.

CLBP is closely related to lumbar muscle degeneration [20-22]. Macroscopically, this muscle degeneration is characterized by a decrease in cross-sectional area [2327] and an increase in the fat content [28-30] of the lumbar paraspinal muscles. In addition to macroscopic changes, it has been proposed that microscopic changes can also occur in patients with nonspecific LBP. Patients with severe pain have a higher portion of type IIX (fast twitch glycolytic, previously called type IIB) at the expense of type I (slow twitch oxidative) fibers [31]. Hence, the changes in fiber type, could lead to lowered fatigue resistance of the paraspinal muscles, which in turn results in higher vulnerability of the lumbar spine [32].

The lumbodorsal muscles are mainly composed of the multifidus, longissimus, iliocostalis and quadratus lumborum. Magnetic resonance imaging (MRI) is considered the standard method of imaging for the assessment of posterior trunk muscles. MRI can provide clear images of not only anatomical structures but also boundaries of different tissues. However, the long waiting time for an appointment, long examination time and high examination cost limit its use in routine clinical applications[33]. Additionally, it is difficult to dynamically evaluate the lumbar and back muscles by MRI. 
Ultrasonography (US) has advanced rapidly over the past 50 years, and it is widely used in the clinic in fields such as gynecology and obstetrics and other fields in which abdominal and superficial organs, cardiovascular structures, and especially musculoskeletal structures are examined. For instance, US has been used to directly assess atrophy and hypertrophy in different muscles[34]. US imaging has obvious advantages over other imaging techniques: it is noninvasive, does not use radiation, can be used to acquire images in multiple planes, has low examination costs, and most importantly, can dynamically assess the shrinkage of lumbodorsal muscles during contractions and relaxation in real time, which cannot be achieved by MRI[33, 35]. Muscle thickness often increases by varying degrees as it contracts. Existing studies have reported that ultrasonography can be used to observe changes in the thickness of muscles, except for lumbodorsal muscles, during contractions and relaxation to detect or measure muscle "activity" $[34,36]$.

However, currently, there is no uniform, simple, feasible method for assessing lumbodorsal muscle activity. Does yoga yield significant changes in the lumbar muscle? Which muscle groups are most affected by a particular type of yoga? Are certain imaging methods appropriate for specific evaluations?

Thus, we need to identify a way to objectively assess exercise effectiveness. We chose the locust yoga pose (Fig. 1) as the contracted state and the prone position as the resting state. The main purposes of this study were to use real-time ultrasound to observe the changes in the thicknesses of lumbodorsal muscles dynamically in contracted and relaxed states, to determine which muscle has the highest contraction ratio of change, and to determine whether ultrasound can be effective for examining the lumbar muscle.

This study provides a theoretical basis for further ultrasonic assessment of the changes in lumbodorsal muscles in patients with pain and of the changes in lumbodorsal muscles after yoga exercise. To provide imaging support for the diagnosis and differential diagnosis of CLBP, to evaluate of yoga exercise results, and the etiological mechanism can be further explored.

\section{Methods}

From May 2019 to August 2019, a total of 200 volunteers (with no history of neurological, cognitive, metabolic, cardiovascular, pulmonary, or low back musculoskeletal impairment) volunteered to participate in this study and were recruited continuously and randomly from the Physical Examination Center of the Seventh Affiliated Hospital of Sun Yat-sen University. Fiftytwo healthy volunteers, ranging in age from 19 to 68 (age: $40 \pm 8$ years; weight: $63.3 \pm 5.2 \mathrm{~kg}$; height: $170.2 \pm$ $13.1 \mathrm{~cm})$ ) and including 23 males and 29 females, were included in the study. The other volunteers were excluded because they had current or chronic LBP; had a history of back surgery; had a serious spinal pathology, such as fracture, cancer, or infection; or did not agree to sign in the informed consent form. All participants underwent ultrasound to assess lumbodorsal muscles using a $3.6 \mathrm{MHz}$ convex array probe with an ultrasound coupler (DC-6, made in 2018, Mindray, Mindray Biomedical Electronics Co., Ltd., Shenzhen, China).

Each eligible participant was informed of all experimental procedures and provided informed written consent. In addition, information about their height and weight was obtained before the examination. All subjects were trained to master the completely relaxed state and the posture of the locust yoga pose.

\section{Relaxed state}

For the relaxed state, subjects laid flat on the examination bed in the prone position, with both of their arms resting naturally to the sides of their body, their head slightly resting to one side, and their legs relaxed.

\section{Locust pose}

For the locust pose, participants laid in a prone position, with their hands pronated, shoulder blades retracted together, gaze looking forward and downward, shoulder and elbows extended, spine extended, lower abdomen in contact with the bed surface to act as a fulcrum, hips and legs extended, and feet plantarflexed; both the angle between the lower limbs and the bed surface and the angle between the trunk and the bed surface were maintained to be as close to $30^{\circ}$ as possible. The whole body was bent like an inverted arch (Fig. 1).

\section{Ultrasound procedure}

First, gel was applied for ultrasound, and in the relaxed state, the probe was placed transversely at the upper waist, and the 1st lumbar vertebra was identified according to the 12th rib. Then, the probe was gradually moved downward to observe the general shape of the cross-sections of each lumbodorsal muscle. At the level of the 4th lumbar vertebra, the probe was rotated $90^{\circ}$ clockwise to view a section of each muscle in the sagittal plane. The transducer was oriented in the sagittal plane so that it was parallel to the muscle fibers to the greatest extent possible[37]. The muscles including the multifidus, longissimus, iliocostalis, and quadratus lumborum, were measured in the sagittal plane. Each muscle was measured as vertically as possible along the long axis of the muscle fibers to reduce measurement errors due to angulation. All eight muscles on both sides of the lower back were measured sequentially, from shallow to deep, from middle to side, first left and then right. The order 


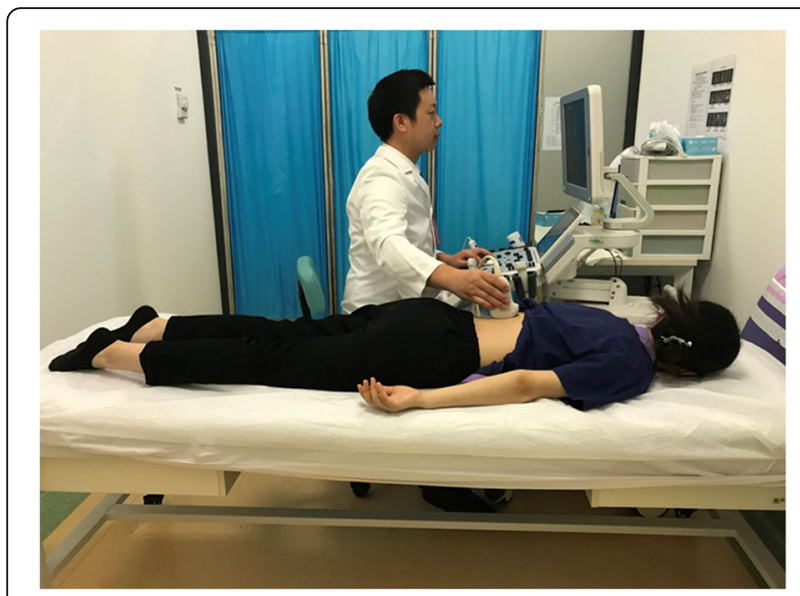

Fig. 1 The head is lifted upward as much as possible, and both the upper limbs and lower limbs are stretched out from the bed surface. The lower abdomen is in contact with the bed surface to act as the fulcrum. The angle of the lower limbs and fulcrum and the angle of the upper body and fulcrum are close to $30^{\circ}$. The whole body is bent like an inverted arch.

was as follows: the multifidus, the quadratus lumborum, the longissimus and the iliocostalis.

\section{Measure method}

Each subject was in a relaxed state when the optimal sagittal section of each muscle was recorded to ensure that the probe position did not change, and then, the subject was asked to perform the locust yoga pose. To record the optimal sagittal section of each muscle during the contracted state, still images were unified with the double mode[38], and still images in the left diastolic and right contracted states were assessed. The thickness of all the muscles in different positions was measured three times, and then, on the other contraction image, in the same position, the thickness was also measured three times. Finally, the average of the measurements was recorded.

\section{Statistical method}

All examinations and measurements were performed by two sonographers with more than 10 years of ultrasound experience. All data analyses were performed using SPSS statistical software (v.20.0; IBM Corp., Armonk, NY). All data followed a normal distribution. One-way ANOVA was used to compare the differences between the two groups of data (pre-exercise and exercise motion), and the relationship between each of them was also analyzed. A p value of less than 0.05 was considered significant.

\section{Results}

In this study, 52 individuals met the inclusion criteria, including 31 women and 21 men aged 18 to 68 years; the mean age was $40.35 \pm 11.042$ years, and the mean body mass index (BMI) was $23.845 \pm 3.476$. Clear ultrasound images were captured for all volunteers.

The thickness of the muscles, including the multifidus, longissimus, iliocostalis, and quadratus lumborum, in relaxed and contracted states was measured. The mean thicknesses of these muscles in the relaxed and contracted states are shown in Table 1 . The mean thickness of the left multifidus in the relaxed state was $1.32 \pm$ $0.27 \mathrm{~cm}$ (95\% CI: $1.24 \sim 1.39)$, and that in the contracted state was $1.60 \pm 0.30 \mathrm{~cm}(95 \%$ CI: $1.52 \sim 1.69)$ (obviously different between the relaxed and contracted states, $P<$ $0.001)$. The mean thickness of the right multifidus in the relaxed state was $1.37 \pm 0.31 \mathrm{~cm} \mathrm{(95 \%} \mathrm{CI:} 1.29 \sim 2.46)$, and that in the contracted state was $1.68 \pm 0.38 \mathrm{~cm}(95 \%$ CI: $1.58 \sim 1.79)(P<0.005)$. The mean thickness of the left quadratus lumborum in the relaxed quadratus was $1.38 \pm 0.32 \mathrm{~cm}(95 \% \mathrm{CI}: 1.29 \sim 1.47)$, and that in the contracted quadratus lumborum was $1.62 \pm 0.40 \mathrm{~cm}$ (95\% CI: $1.50 \sim 1.73)(P=0.005)$. The mean thickness of the right quadratus lumborum in the relaxed quadratus was $1.30 \pm 0.32 \mathrm{~cm}(95 \% \mathrm{CI}: 1.21 \sim 1.39)$, and that in the contracted quadratus lumborum was $1.55 \pm 0.41 \mathrm{~cm}$ (95\% CI: $1.44 \sim 1.67)(P=0.005)$. The mean thickness of the left longissimus in the relaxed state was $2.33 \pm$ $0.51 \mathrm{~cm}(95 \% \mathrm{CI}: 2.19 \sim 2.47)$, and that in the contracted state was $3.20 \pm 0.61 \mathrm{~cm}(95 \%$ CI: $3.03 \sim 3.37) \quad(P<$ 0.005). The mean thickness of the right longissimus in the relaxed state was $2.34 \pm 0.49 \mathrm{~cm}(95 \% \mathrm{CI}: 2.20$ $2.48)$, and that in the contracted state was $3.26 \pm 0.68 \mathrm{~cm}$ (95\% CI: $3.07 \sim 3.45)(P<0.005)$. The mean thickness of the left iliocostalis in the relaxed state was $1.88 \pm$ $0.41 \mathrm{~cm}(95 \%$ CI: $1.76 \sim 1.99)$, and that in the contracted state was $2.34 \pm 0.49 \mathrm{~cm}(95 \%$ CI: $2.00 \sim 2.47) \quad(P<$ 0.005). The mean thickness of the right iliocostalis in the relaxed state was $1.98 \pm 0.40 \mathrm{~cm}(95 \% \mathrm{CI}: 1.87 \sim 2.09)$, and that in the contracted state was $2.44 \pm 0.56 \mathrm{~cm}(95 \%$ CI: $2.29 \sim 2.60)(P<0.005)$.

The thickness in the contracted state divided by that in the relaxed state is denoted by $\mathrm{C} / \mathrm{R}$, and the mean $\mathrm{C} /$ $\mathrm{R}$ for each muscle is also shown in Table 1. Among these four muscles, the longissimus had the highest $C / R$, and the mean $C / R$ was $1.39 \pm 0.14$ on the left and $1.40 \pm$ 0.16 on the right. The multifidus and iliocostalis had the second highest $C / R$. The mean $C / R$ of the multifidus was $1.23 \pm 0.12$ on the left and $1.24 \pm 0.15$ on the right, and the mean $C / R$ of the iliocostalis was $1.25 \pm 0.12$ on the left and $1.24 \pm 0.14$ on the right. The quadratus lumborum had the lowest $C / R$, and the mean $C / R$ of the quadratus lumborum was $1.17 \pm 0.10$ on the left and $1.19 \pm 0.11$ on the right. The differences between the relaxed and contracted states for all the muscles had a $\mathrm{p}$ value of less than 0.005 (Fig. 2). Figures 2, 3, 4 and 5 show different muscles in the relaxed and contracted states. The blue line indicates the thickness of the 
Table 1 The mean thicknesses of four muscles in the relaxed and contracted states (Unit: centimeter), $95 \%$ confidence interval (CI) in Resting state and Contracted state, the related C/R ratio, and the $\mathrm{p}$ value in differences between the relaxed and contracted states for the four muscles

\begin{tabular}{lllllllll}
\hline & $\begin{array}{l}\text { the left } \\
\text { multifidus }\end{array}$ & $\begin{array}{l}\text { the right } \\
\text { multifidus }\end{array}$ & $\begin{array}{l}\text { the left quadratus } \\
\text { lumborum }\end{array}$ & $\begin{array}{l}\text { the right } \\
\text { quadratus } \\
\text { lumborum }\end{array}$ & $\begin{array}{l}\text { the left } \\
\text { longissimus }\end{array}$ & $\begin{array}{l}\text { the right } \\
\text { longissimus }\end{array}$ & $\begin{array}{l}\text { the left } \\
\text { iliocostalis }\end{array}$ & $\begin{array}{l}\text { the right } \\
\text { iliocostalis }\end{array}$ \\
\hline Resting state & $1.32 \pm 0.27$ & $1.37 \pm 0.31$ & $1.38 \pm 0.32$ & $1.30 \pm 0.32$ & $2.33 \pm 0.51$ & $2.34 \pm 0.49$ & $1.88 \pm 0.41$ & $1.98 \pm 0.40$ \\
Contracted state & $1.60 \pm 0.30$ & $1.68 \pm 0.38$ & $1.62 \pm 0.40$ & $1.55 \pm 0.41$ & $3.20 \pm 0.61$ & $3.26 \pm 0.68$ & $2.34 \pm 0.49$ & $2.44 \pm 0.56$ \\
$\begin{array}{l}95 \% \text { Cl in } \\
\text { Resting state }\end{array}$ & $1.24 \sim 1.39$ & $1.29 \sim 2.46$ & $1.29 \sim 1.47$ & $1.21 \sim 1.39$ & $2.19 \sim 2.47$ & $2.20 \sim 2.48$ & $1.76 \sim 1.99$ & $1.87 \sim 2.09$ \\
$95 \%$ Cl in & $1.52 \sim 1.69$ & $1.58 \sim 1.79$ & $1.50 \sim 1.73$ & $1.44 \sim 1.67$ & $3.03 \sim 3.37$ & $3.07 \sim 3.45$ & $2.00 \sim 2.47$ & $2.29 \sim 2.60$ \\
Contracted state & & & & & & & \\
C/R & $1.23 \pm 0.12$ & $1.24 \pm 0.15$ & $1.17 \pm 0.10$ & $1.19 \pm 0.11$ & $1.39 \pm 0.14$ & $1.40 \pm 0.16$ & $1.25 \pm 0.12$ & $1.24 \pm 0.14$ \\
$F$ & 26.49 & 21.14 & 10.71 & 11.54 & 62.17 & 62.11 & 26.34 & 23.63 \\
$P$ & $<0.001$ & $<0.001$ & $=0.001$ & $=0.001$ & $<0.001$ & $<0.001$ & $<0.001$ & $<0.001$ \\
\hline
\end{tabular}
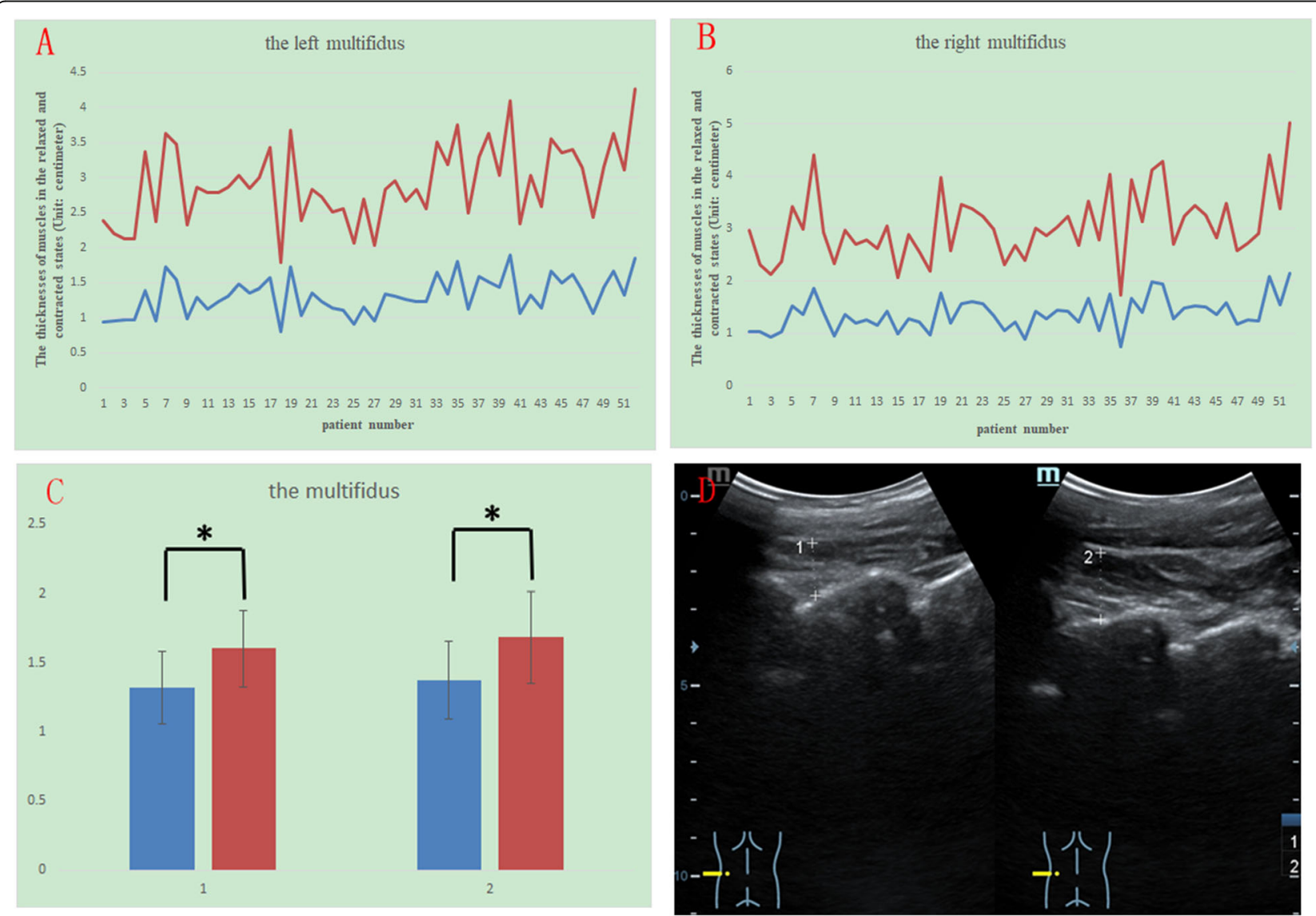

Fig. 2 The thicknesses of the left (Fig. 2 A) and right (Fig. 2B) multifidus in the resting (blue line) and contracted conditions (red line). Comparison of the thicknesses in the resting (blue column) and contracted conditions (red column). Group 1 is right, and group 2 is left (Fig. 2 C). The sonogram of the multifidus: left shows the relaxed state, and right shows the contracted state (Fig. 2D) 

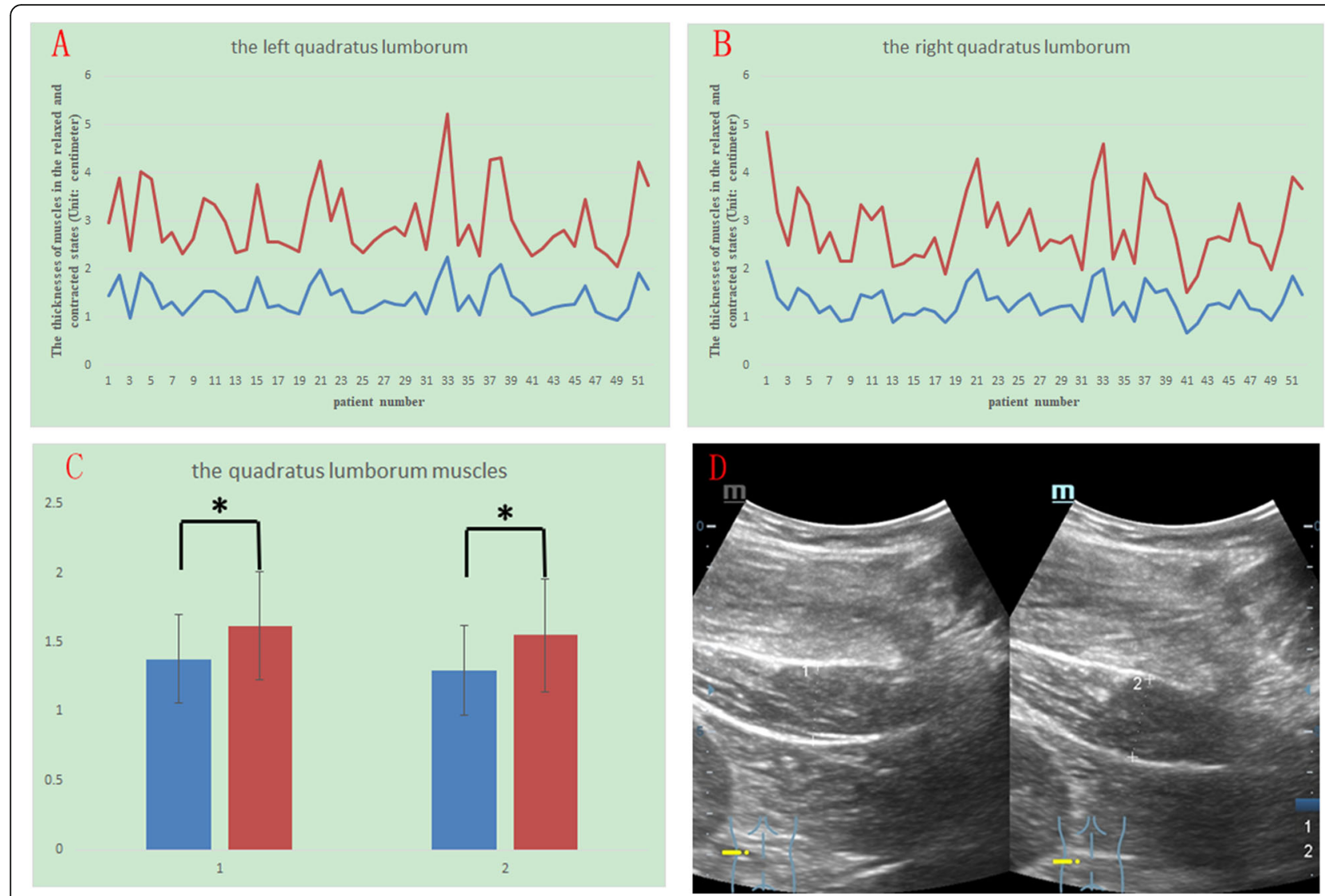

Fig. 3 The thicknesses of the left (Fig. 3 A) and right (Fig. 3B) quadratus lumborum muscles in the resting (blue line) and contracted conditions (red line). Comparison of the thicknesses in the resting (blue column) and contracted conditions (red column). Group 1 is right, and group 2 is left (Fig. 3 C). The sonogram of the quadratus lumborum: left shows the relaxed state, and right shows the contracted state (Fig. 3D)

muscle in the relaxed state. The red line indicates the thickness of the muscle in the contracted state.

\section{Discussion}

In the past, researchers studying CLBP have comprehensively assessed the vertebrae, discs, and intervertebral joints of the back. Nevertheless, the importance of the lumbodorsal muscles in stabilizing the lumbar spine should not be underestimated[20,39], and this viewpoint was excellently illustrated in a study that provided quantitative data about the stabilizing effects of muscles with regard to the mechanics of the spine. Moreover, previous studies have shown that the lumbar muscles often degenerate to different degrees when patients suffer from the pain[20]. Changes in structure may lead to changes in muscle fiber elasticity, which inevitably affect muscle function. Even without changes in muscle structure, pain causes pain-related nerve suppression, and the level of activity of lumbar muscles decreases to prevent tissue damage[40], thereby affecting muscle contractile function. Therefore, it can be assumed that patients with CLBP exhibit changes in muscle contractile function to a certain

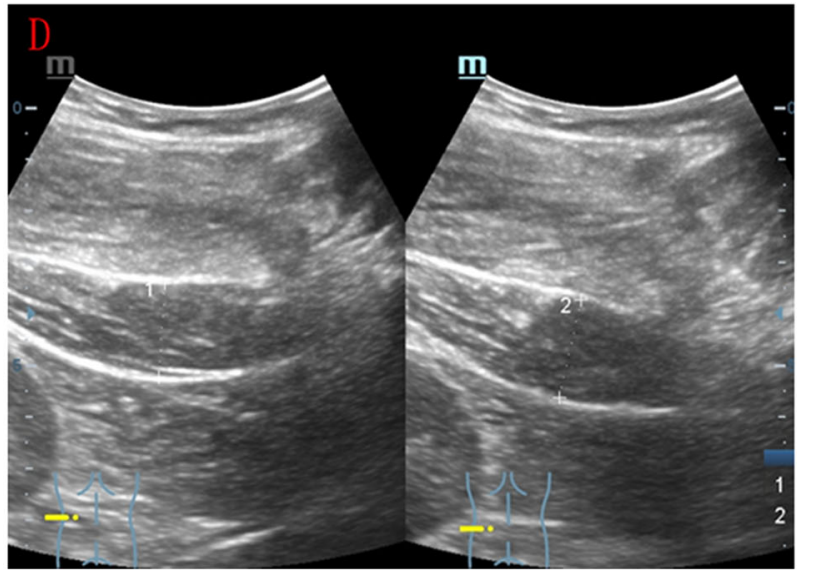

extent, regardless of whether there are morphological structural changes or how the structure changes.

Yoga has been widely accepted by clinicians, and patients could reduce pain with CLBP[11-18]. Kliziene et al. found that after eight months of core stability training, the cross-sectional area of the multifidus muscle increased by $22 \%[41]$. However, it is not clear how lumbar muscle contractions change when doing yoga, and the effects of locust yoga pose and its relation between muscle thicknesses are not clear.

As actin and myosin filaments overlap more during muscle contractions than during relaxation, the muscle generally becomes thicker and shorter[42, 43]. Real-time ultrasound can be used to observe dynamic changes in muscle thickness from relaxed to contracted states. The contraction ratio can be calculated according to the muscle thickness in the two different states to quantitatively evaluate muscle contractile function[34, 44].

Therefore, in this study, we focused on the changes in the lumbar muscles when people perform yoga. We used ultrasound to assess changes in lumbar muscle relaxation and contraction during the locust pose in a normal population. The establishment of this model allowed 

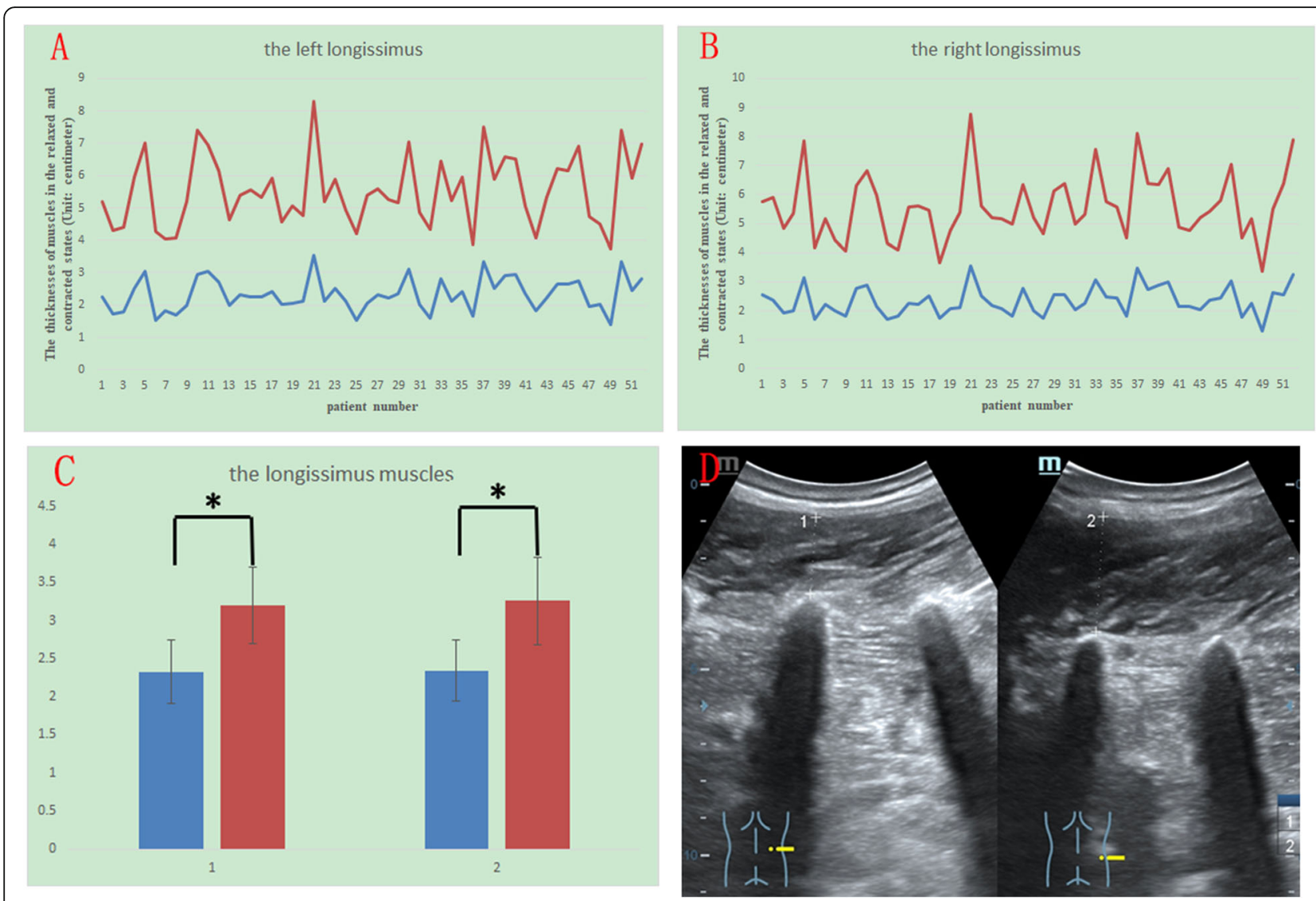

Fig. 4 The thicknesses of the left (Fig. 4 A) and right (Fig. 4B) longissimus muscles in the resting (blue line) and contracted conditions (red line). Comparison of the thicknesses in the resting (blue column) and contracted conditions (red column). Group 1 is right, and group 2 is left (Fig. 4 C). The sonogram of the longissimus: left shows the relaxed state, and right shows the contracted state (Fig. 4D)

data regarding the contraction state of the lumbar muscle to be obtained in a normal population, and based on this, future studies can further explore and evaluate the contraction state of CLBP patients, the lumbar muscle after yoga exercise, the effect exercise on lumbar instability and on a patient population after lumbar operation.

In the existing literature on lumbodorsal muscles, the posture in which patients were examined differed among studies. Some evaluations were performed in an upright position, while others were performed in a prone or supine position. In the supine position, which is often used for MRI and CT scans, the back muscles are often compressed and deformed due to the patient's body weight. In the upright position, the human body needs small levels of muscular activity to maintain the pose, which might affect the thicknesses of lumbar muscles[22]. Furthermore, in the standing and supine positions, it is difficult to observe and measure changes in lumbodorsal muscles with US. Therefore, the prone position was chosen for our study. With subjects in the prone position, we can ensure that there are no additional contractions of the muscles in the relaxed state, and it is convenient for taking measurements.
Yoga has been widely accepted, however, yoga contains a variety of postures[45], and we assume that each posture targets different muscles. According to our experience in clinical practice, the locust yoga pose is an effective exercise to relieve CLBP. We chose the locust yoga pose as the contracted state for the following three primary reasons. First, the locust yoga pose is effective in relieving pain. Second, the action is simple and easy to perform. Third, it is convenient for us to observe and measure muscles during this pose.

In our study, the data objectively showed that the locust yoga pose can be used to exercise the lumbar back muscles, especially the longissimus. According to the measurements of the thickness of lumbodorsal muscles taken in a uniform manner during the locust pose, the contraction ratio of each muscle $(\mathrm{C} / \mathrm{R})$ was calculated to uniformly quantify the contraction function of each muscle.

However, our study has some limitations. First, yoga involves various poses; in this study, we investigated only the locust pose. Second, the sample size was relatively small, so a study with a larger sample size needs to be conducted to determine the normal range of the contraction 

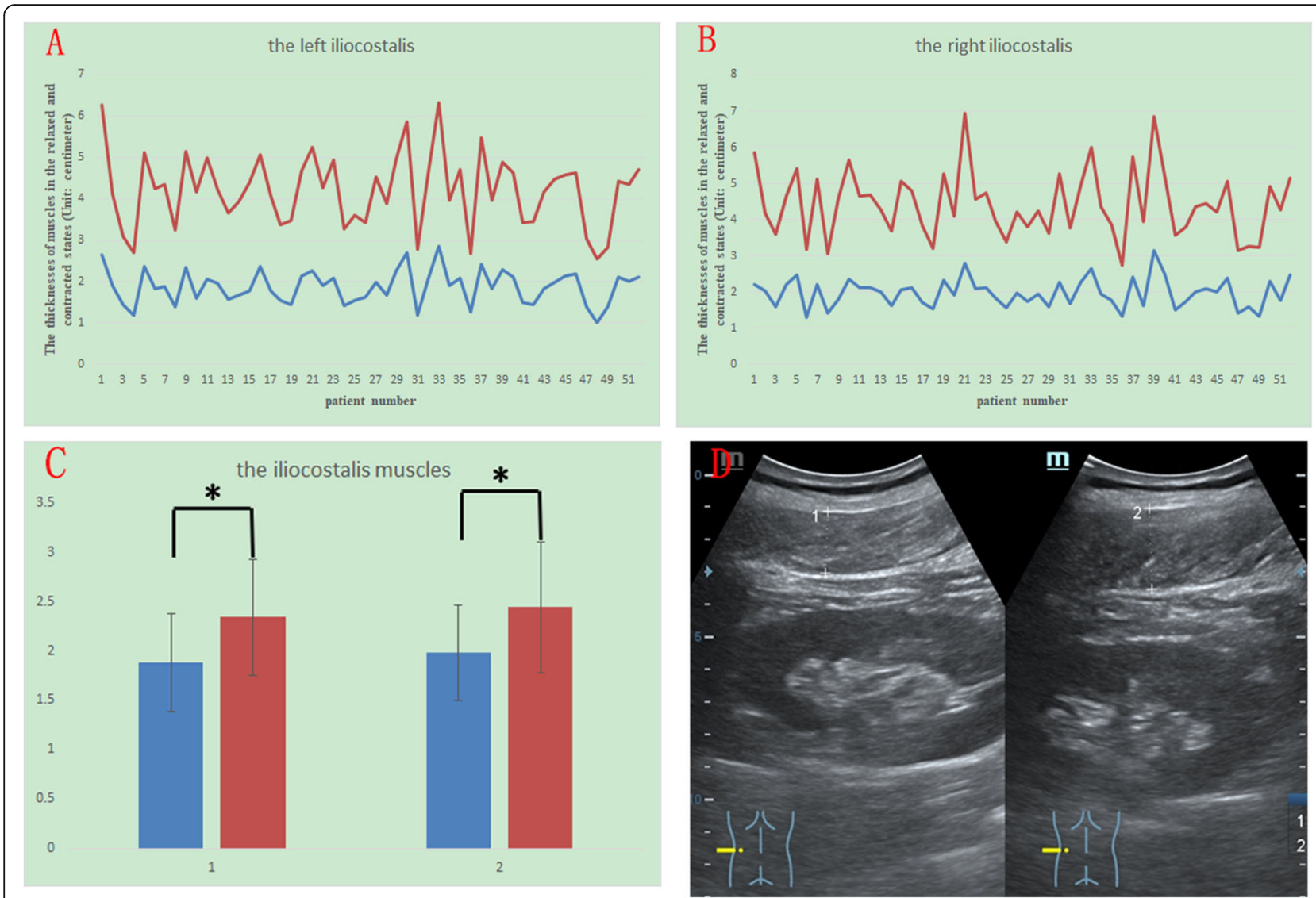

Fig. 5 The thicknesses of the left (Fig. 5 A) and right (Fig. 5B) iliocostalis muscles in the resting (blue line) and contracted conditions (red line). Comparison of the thicknesses in the resting (blue column) and contracted conditions (red column). Group 1 is right, and group 2 is left (Fig. 5 C). The sonogram of the iliocostalis: left shows the relaxed state, and right shows the contracted state (Fig. 5D)

ratio of each muscle. Third, the subjects of this study were normal people without pain. Some patients may not be able to perform the exercise mentioned above and therefore may not be eligible for future studies. Additionally, this posture may not be suitable for US measurement of the lumbosacral muscles for patients, such as spinal stenosis, facet problems, tumors and fractures.

\section{Conclusions}

Ultrasound can be used to dynamically assess the contractile function of the lumbar muscle in the locust pose of yoga, the $C / R$ ratio can be used to indicate the ability of a muscle to contract, and dynamic ultrasound can guide lumbar exercise and feedback the exercise results. The establishment of this model allowed data regarding the contraction state of the lumbar muscle to be obtained in a normal population, and based on this, future studies can further explore and evaluate the contraction state of CLBP patients, the lumbar muscle after yoga exercise, the effect exercise on lumbar instability and on a patient population after lumbar operation.

\section{Abbreviations}

BMI : body mass index; C/R: contracted state/resting state; CSAs: crosssectional areas; LBP: low back pain; CLBP: chronic LBP; MRI: magnetic resonance imaging; US: ultrasonography

\section{Acknowledgements}

We wish to thank the models in Fig. 1.

\section{Authors' contributions}

$W L, Y Z$ and $Z X$ conceived of the presented idea. $W L$ and $Z X$ performed the ultrasound testing. $W L$ and $J L$ analyzed the results and wrote the manuscript. XZ, NC and $\mathrm{HO}$ performed the calculations and statistical data. All authors discussed the results and contributed to the final version of the manuscript. The author(s) read and approved the final manuscript.

\section{Funding}

This study was funded by the Seventh Affiliated Hospital of SYSU, Clinical Research Fund (ZSQYLCKYJJ202018). The funders have had no role in the design of the study, nor will they have any role in the collection, analysis and interpretation of the data or in the writing of the manuscript.

\section{Availability of data and materials}

The datasets used or analyzed during the current study are available from the corresponding author on reasonable request. 


\section{Declarations}

\section{Ethics approval and consent to participate}

The study was approved by the Ethics Committees of the Seventh Affiliated Hospital of Sun Yat-sen University. All procedures were carried out in accordance with ethical standards. Written informed consent was obtained from all individual participants included in the study.

\section{Consent for publication}

All participants, including those depicted in Fig. 1, gave written and informed consent for publication for all personal or clinical details along with any identifying images to be published in this study.

\section{Competing interest}

The authors have no conflicts of interest to declare.

\section{Author details}

${ }^{1}$ Shenzhen Hospital, Southern Medical University, Shenzhen, China. ${ }^{2}$ The Third School of Clinical Medicine, Southern Medical University, Guangzhou, China. ${ }^{3}$ Department of Ultrasound, The Seventh Affiliated Hospital of Sun Yat-Sen University, 628\# Zhenyuan Road, 518100 Shenzhen, Guangdong, China. ${ }^{4}$ Department of Orthopedics, The Seventh Affiliated Hospital of Sun Yat-Sen University, 628\# Zhenyuan Road, 518100 Shenzhen, Guangdong, China. ${ }^{5}$ Department of Microsurgery, Orthopedic Trauma and Hand Surgery, The First Affiliated Hospital, Sun Yat- sen University, No. 58, Zhongshan 2nd Road, 510080 Guangzhou, China. ${ }^{6}$ Department of Gastroenterology, The Seventh Affiliated Hospital of Sun Yat-Sen University, 628\# Zhenyuan Road, 518100 Shenzhen, Guangdong, China. ${ }^{7}$ Department of Ultrasound, Shenzhen Hospital, Southern Medical University, No. 1333, Xinhu Road, Xinan Street, Baoan District, Shenzhen, China.

Received: 1 November 2020 Accepted: 15 July 2021

Published online: 10 August 2021

\section{References}

1. van Tulder $M$, Becker $A$, Bekkering $T$, et al. Chapter 3. European guidelines for the management of acute nonspecific low back pain in primary care. Eur Spine J. 2006;15(Suppl 2):169-91.

2. Owen PJ, Miller CT, Mundell NL, et al. Which specific modes of exercise training are most effective for treating low back pain? Network metaanalysis. Br J Sports Med. 2020;54:1279-87.

3. Maher C, Underwood M, Buchbinder R. Non-specific low back pain. Lancet 2017:389:736-47.

4. Hoy D, March L, Brooks $P$, et al. The global burden of low back pain: estimates from the Global Burden of Disease 2010 study. Ann Rheum Dis. 2014;73:968-74.

5. Global, regional, and national incidence, prevalence, and years lived with disability for 301 acute and chronic diseases and injuries in 188 countries, 1990-2013: a systematic analysis for the Global Burden of Disease Study 2013. Lancet. 2015;386:743-800

6. KADER DF, Wardlaw D, Smith FW. Correlation between the MRI changes in the lumbar multifidus muscles and leg pain. Clin Radiol. 2000;55:145-9.

7. Smidt N, de Vet HC, Bouter LM, et al. Effectiveness of exercise therapy: a best-evidence summary of systematic reviews. Aust J Physiother. 2005;51: 71-85.

8. Boucher JA, Preuss R, Henry SM, Dumas JP, Lariviere C. The effects of an 8week stabilization exercise program on lumbar movement sense in patients with low back pain. BMC Musculoskelet Disord. 2016:17:23.

9. Chou R, Huffman LH. Nonpharmacologic therapies for acute and chronic low back pain: a review of the evidence for an American Pain Society/ American College of Physicians clinical practice guideline. Ann Intern Med. 2007;147:492-504

10. Airaksinen O, Brox Jl, Cedraschi C, et al. Chapter 4. European guidelines for the management of chronic nonspecific low back pain. Eur Spine J. 2006; 15(Suppl 2):192-300.

11. Saper RB, Sherman KJ, Cullum-Dugan D, Davis RB, Phillips RS, Culpepper L. Yoga for chronic low back pain in a predominantly minority population: a pilot randomized controlled trial. Altern Ther Health Med. 2009;15:18-27.

12. Tilbrook $\mathrm{HE}$, Cox H, Hewitt CE, et al. Yoga for chronic low back pain: a randomized trial. Ann Intern Med. 2011;155:569-78.
13. Saragiotto BT, Yamato TP, MAHER C. Yoga for low back pain: PEDro systematic review update. Br J Sports Med. 2015:49:1351.

14. Chang DG, Kertesz SG. Yoga and Low Back Pain: No Fool's Tool. Ann Intern Med. 2017;167:129-30

15. Groessl EJ, Liu L, Chang DG, et al. Yoga for Military Veterans with Chronic Low Back Pain: A Randomized Clinical Trial. Am J Prev Med. 2017;53:599-608.

16. Saper RB, Lemaster C, Delitto A, et al. Yoga, Physical Therapy, or Education for Chronic Low Back Pain: A Randomized Noninferiority Trial. Ann Intern Med. 2017;167:85-94.

17. Grotle M, Hagen KB. Yoga classes may be an alternative to physiotherapy for people with chronic nonspecific low back pain [synopsis]. J Physiother. 2018;64:57.

18. MUNK R. Yoga classes may be an alternative to physiotherapy for people with chronic nonspecific low back pain [commentary]. J Physiother. 2018;64:57.

19. Wieland LS, Skoetz N, Pilkington K, Vempati R, D'adamo CR, Berman BM Yoga treatment for chronic non-specific low back pain. Cochrane Database Syst Rev. 2017;1:D10671.

20. Danneels LA, Vanderstraeten GG, Cambier DC, Witvrouw EE, De Cuyper HJ. CT imaging of trunk muscles in chronic low back pain patients and healthy control subjects. Eur Spine J. 2000;9:266-72.

21. Parkkola R, Rytokoski U, Kormano M. Magnetic resonance imaging of the discs and trunk muscles in patients with chronic low back pain and healthy control subjects. Spine (Phila Pa 1976). 1993;18:830-36.

22. Goubert D, Oosterwijck JV, Meeus M, Danneels L. Structural Changes of Lumbar Muscles in Non-specific Low Back Pain: A Systematic Review. Pain Physician. 2016;19:E985-1000.

23. Hides JA, Stokes MJ, Saide M, Jull GA, Cooper DH. Evidence of lumbar multifidus muscle wasting ipsilateral to symptoms in patients with acute/ subacute low back pain. Spine (Phila Pa 1976). 1994;19:165-72.

24. Hides J, Gilmore C, Stanton W, Bohlscheid E. Multifidus size and symmetry among chronic LBP and healthy asymptomatic subjects. Man Ther. 2008;13:43-9.

25. Fortin M, Macedo LG. Multifidus and paraspinal muscle group crosssectional areas of patients with low back pain and control patients: a systematic review with a focus on blinding. Phys Ther. 2013:93:873-88.

26. Ploumis A, Michailidis N, Christodoulou P, Kalaitzoglou I, Gouvas G, Beris A. Ipsilateral atrophy of paraspinal and psoas muscle in unilateral back pain patients with monosegmental degenerative disc disease. Br J Radiol. 2011; 84:709-13.

27. Barker KL, Shamley DR, Jackson D. Changes in the cross-sectional area of multifidus and psoas in patients with unilateral back pain: the relationship to pain and disability. Spine (Phila Pa 1976). 2004;29:E515-19.

28. Chan ST, Fung PK, Ng NY, et al. Dynamic changes of elasticity, crosssectional area, and fat infiltration of multifidus at different postures in men with chronic low back pain. Spine J. 2012;12:381-88.

29. Yanik B, Keyik B, Conkbayir I. Fatty degeneration of multifidus muscle in patients with chronic low back pain and in asymptomatic volunteers: quantification with chemical shift magnetic resonance imaging. Skeletal Radiol. 2013;42:771-78

30. Mengiardi B, Schmid MR, Boos N, et al. Fat content of lumbar paraspinal muscles in patients with chronic low back pain and in asymptomatic volunteers: quantification with MR spectroscopy. Radiology. 2006;240:786-92

31. Mannion AF, Connolly B, Wood K, Dolan P. The use of surface EMG power spectral analysis in the evaluation of back muscle function. J Rehabil Res Dev. 1997;34:427-39.

32. Mannion AF. Fibre type characteristics and function of the human paraspinal muscles: normal values and changes in association with low back pain. J Electromyogr Kinesiol. 1999;9:363-77.

33. Sions JM, Teyhen DS, Hicks GE. Criterion Validity of Ultrasound Imaging: Assessment of Multifidi Cross-Sectional Area in Older Adults With and Without Chronic Low Back Pain. J Geriatr Phys Ther. 2017:40:74-9.

34. Hodges PW, Pengel LH, Herbert RD, Gandevia SC. Measurement of muscle contraction with ultrasound imaging. Muscle Nerve. 2003;27:682-92.

35. Ghamkhar L, Emami M, Mohseni-Bandpei MA, Behtash H. Application of rehabilitative ultrasound in the assessment of low back pain: a literature review. J Bodyw Mov Ther. 2011;15:465-77.

36. Critchley D. Instructing pelvic floor contraction facilitates transversus abdominis thickness increase during low-abdominal hollowing. Physiother Res Int. 2002:7:65-75.

37. Creze M, Nyangoh TK, Gagey O, Bellin MF, Rocher L, Soubeyrand M Feasibility assessment of shear wave elastography to lumbar back muscles: A Radioanatomic Study. Clin Anat. 2017;30:774-80. 
38. Sions JM, Velasco TO, Teyhen DS, Hicks GE. Reliability of ultrasound imaging for the assessment of lumbar multifidi thickness in older adults with chronic low back pain. J Geriatr Phys Ther. 2015;38:33-9.

39. Cholewicki J, Mcgill SM. Mechanical stability of the in vivo lumbar spine: implications for injury and chronic low back pain. Clin Biomech (Bristol Avon). 1996;11:1-15.

40. Rantanen J, Hurme M, Falck B, et al. The lumbar multifidus muscle five years after surgery for a lumbar intervertebral disc herniation. Spine (Phila Pa 1976). 1993;18:568-74.

41. Kliziene I, Sipaviciene S, Klizas S, Imbrasiene D. Effects of core stability exercises on multifidus muscles in healthy women and women with chronic low-back pain. J Back Musculoskelet Rehabil. 2015;28:841-47.

42. Koppenhaver SL, Hebert JJ, Parent EC, Fritz JM. Rehabilitative ultrasound imaging is a valid measure of trunk muscle size and activation during most isometric sub-maximal contractions: a systematic review. Aust J Physiother. 2009:55:153-69

43. Herbert RD, Moseley AM, Butler JE, Gandevia SC. Change in length of relaxed muscle fascicles and tendons with knee and ankle movement in humans. J Physiol. 2002;539:637-45.

44. Koppenhaver S, Kniss J, Lilley D, et al. Reliability of ultrasound shear-wave elastography in assessing low back musculature elasticity in asymptomatic individuals. J Electromyogr Kinesiol. 2018:39:49-57.

45. Chopp-hurley JN, Prophet C, Thistle B, Pollice J, Maly MR. Scapular Muscle Activity During Static Yoga Postures. J Orthop Sports Phys Ther. 2018;48: 504-09.

\section{Publisher's Note}

Springer Nature remains neutral with regard to jurisdictional claims in published maps and institutional affiliations.

Ready to submit your research? Choose BMC and benefit from:

- fast, convenient online submission

- thorough peer review by experienced researchers in your field

- rapid publication on acceptance

- support for research data, including large and complex data types

- gold Open Access which fosters wider collaboration and increased citations

- maximum visibility for your research: over $100 \mathrm{M}$ website views per year

At $\mathrm{BMC}$, research is always in progress.

Learn more biomedcentral.com/submissions 